\title{
COVID-19 and Cystic Fibrosis: Diagnostic Difficulties or Incorrect Methods?
}

\author{
Samuel Pecho-Silva ${ }^{1,2}$ (D) Ana Claudia Navarro-Solsol ${ }^{3}$ (D), \\ Vicky Panduro-Correa ${ }^{4}$, Kovy Arteaga-Livias ${ }^{2,4}$ (D), \\ Alfonso J. Rodriguez-Morales ${ }^{2,5,6, *}$ (i) and Kuldeep Dhama ${ }^{7}$
}

${ }^{1}$ Hospital Nacional Edgardo Rebagliati Martins, Lima, Peru. ${ }^{2}$ Universidad Cientifica del Sur. Lima, Peru. ${ }^{3}$ Universidad Nacional de Ucayali. Pucallpa, Peru. ${ }^{4}$ Facultad de Medicina, Universidad Nacional Hermilio Valdizan. Huanuco, Peru. ${ }^{5}$ Public Health and Infection Research Group, Faculty of Health Sciences, Universidad Tecnologica de Pereira, Pereira, Risaralda, Colombia. ${ }^{6}$ Grupo de Investigacion Biomedicina, Faculty of Medicine, Fundacion Universitaria Autonoma de las Americas, Pereira, Risaralda, 660004, Colombia. ${ }^{7}$ Division of Pathology, ICAR-Indian Veterinary Research Institute, Izatnagar, Bareilly - 243 122, Uttar Pradesh, India.

\begin{abstract}
Cystic fibrosis (CF) is a chronic lung disease with wide distribution worldwide. With the appearance of the Coronavirus Disease 2019 (COVID-19), caused by the Severe Acute Respiratory Syndrome Coronavirus 2 (SARS-CoV-2), difficulties arise when evaluating, diagnosing, and treating patients with other conditions, including CF. We present the case of a patient with CF who had a definite serological diagnosis, a CT scan suggestive of SARS-CoV-2 infection/COVID-19, and a negative molecular test (RTPCR), with rapid resolution of symptoms and early discharge. CF/SARS-CoV-2 comorbidity needs to be adequately studied and assessed in the context of the COVID-19 pandemic.
\end{abstract}

Keywords: Cystic fibrosis, COVID-19, SARS-CoV-2, Serological tests, pandemic, Peru, Latin America

\begin{abstract}
*Correspondence: arodriguezm@utp.edu.co
(Received: May 20, 2020; accepted: July 07, 2020)

Citation: Pecho-Silva S, Navarro-Solsol AC, Panduro-Correa V, Arteaga-Livias K, Rodriguez-Morales AJ, Dhama K. COVID-19 and Cystic Fibrosis: Diagnostic Difficulties or Incorrect Methods?. J Pure Appl Microbiol. 2020;14(3):1681-1685. doi: 10.22207/ JPAM.14.3.06

(C) The Author(s) 2020. Open Access. This article is distributed under the terms of the Creative Commons Attribution 4.0 International License which permits unrestricted use, sharing, distribution, and reproduction in any medium, provided you give appropriate credit to the original author(s) and the source, provide a link to the Creative Commons license, and indicate if changes were made.
\end{abstract}




\section{INTRODUCTION}

Until the year 2019, about 80,000 patients with cystic fibrosis (CF) corresponding to the United States and Europe were registered, the number of CF patients in America is not precisely known (1). CF patients have multiple events of viral, fungal, and bacterial infections throughout their lives, with chronic diseases due to Pseudomonas aeruginosa, Burkholderia cepacia, and Staphylococcus aureus being the most frequent. These recurrent infections are associated with pulmonary exacerbations (PE) that are the leading cause of death in $\mathrm{CF}^{1,2}$. Viral infections are estimated to cause between 10 to $60 \%$ of PE. Unfortunately, samples are not usually taken to assess the presence of viruses ${ }^{3}$. The infections described in the PE of CF patients are the respiratory syncytial virus, human rhinovirus, influenza types $A$ and $B$, parainfluenza virus, human metapneumovirus, picornavirus, coronavirus, and coxsackie/echovirus, which are responsible for continually keeping inflammatory markers elevated during mixed exacerbations, causing antibiotic treatments to be prolonged ${ }^{2-5}$.

The Coronavirus Disease 2019 (COVID-19), caused by the Severe Acute Respiratory Syndrome Coronavirus 2 (SARS-CoV-2) begun on December 30 by the Wuhan health authorities, spreading to most countries of the world and as of May 19, 2020, it has affected more than 4.83 million people and caused the death of more 319 thousand cases $^{6}$. However, there is very little literature that described the presence of this disease in patients with chronic lung diseases and specifically CF/ SARS-CoV-2 comorbidity. The influence of chronic lung diseases on serological tests; therefore, we present the case of pulmonary exacerbation in a CF patient who tested positive for SARS-CoV-2 antibodies.

\section{Case}

A 20-year-old female patient diagnosed with CF from childhood through 2 tests for positive sweat chlorine and a genetic study with a homozygous DeltaF508 mutation. She is a continuous, home oxygen user. At the pulmonary level, he presented bilateral cystic and cylindrical bronchiectasis with marked derangement of the right upper and middle lobe. In the lower portions, she shows bronchoceles and compensatory emphysema, predominantly left. Additionally, she presents with chronic multidrug-resistant Pseudomonas aeruginosa infection, exocrine pancreatic insufficiency, and pulmonary hypertension. In stable PE-free periods, its treatment consists of inhaled tobramycin and colistin and azithromycin three times a week as an immunomodulator. The patient is treated in a national CF referral hospital.

At the beginning of the national health crisis in Peru, due to SARS-CoV-2, the patient was hospitalized on March 10, 2020, for a new PE. A SARS-CoV-2 infection was not considered probable because upon admission to Peru, there
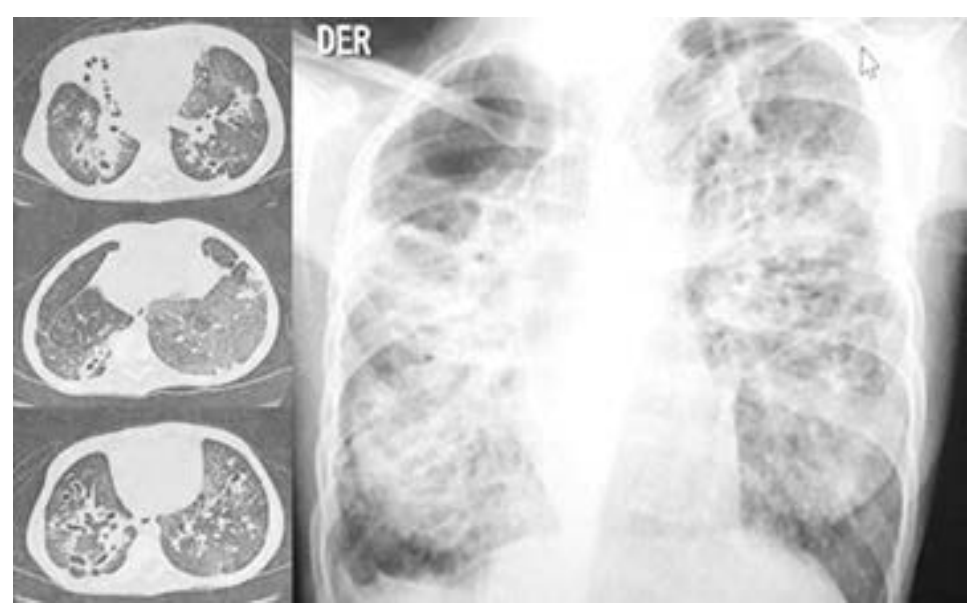

Fig. 1. CT-scan and Chest X-ray of April 2020, with described findings. 
were only 11 cases nationwide, and she did not meet the epidemiological criteria. The patient received intravenous antibiotic treatment with aztreonam, meropenem, and colistin, directed against Pseudomonas aeruginosa. After 21 days of treatment, on April 1, 2020, the patient was discharged after completing the antibiotic treatment, finding herself stable and improved.

On April 23, 2020, she went to a private clinic because she had three days of headache and dizziness, with a slight increase in dyspnea. She was clinically stable with normal vital functions except for a resting heart rate of 114 per minute, which is normal for her. There was no fever or pharyngeal pain. The most representative auxiliary tests were: Leukocytes: 15,190 cell/ $\mu \mathrm{L}$ and hemoglobin: $8 \mathrm{~g} /$ dl. Platelets at 365,000 cell $/ \mu \mathrm{L}$, lymphocytes 2,278 cell/ $\mu \mathrm{L}(15 \%)$, neutrophils 607 cell $/ \mu \mathrm{L}(4 \%)$ and segmented $10,784 \mathrm{cell} / \mu \mathrm{l}(71 \%)$. The arterial gas study showed: ionic calcium $106 \mathrm{mmol} / \mathrm{L}$. Chlorine $83.3 \mathrm{mmol} / \mathrm{L}, \mathrm{pH} 7.34, \mathrm{PaCO}_{2} 75.5 \mathrm{mmHg}$. HCO3 $48.3 \mathrm{mmol} / \mathrm{L}$, lactate $1.9 \mathrm{mmol} / \mathrm{L}$ (normal range, 0.5-2.2). Base Excess: $22.5 \mathrm{mmol} / \mathrm{L}$. $\mathrm{PaO}_{2} 75.5$ $\mathrm{mmHg}$ breathing an inhaled oxygen concentration of $40 \%$. D-dimer: $0.91 \mu \mathrm{g} / \mathrm{mL}$ (normal range 0.0 0.5). LDH 125 U/L. C-Reactive Protein: 4.02 mg/ $\mathrm{dL}$ (normal range 0.0-0.5). Procalcitonin: $0.04 \mathrm{ng} /$ $\mathrm{ml}$ (normal range 0.0-0.5). Ferritin: $48.1 \mathrm{ng} / \mathrm{ml}$ (normal range 13.0-150.0). The marked elevation of $\mathrm{PaCO}_{2}$ is highlighted, which is not usual in the patient.

A SARS-CoV-2 infection study was performed using immunochromatographic methods to detect antibodies in serum. Positive
IgG and negative IgM antibodies were found. She was admitted to a personal isolation room and started antibiotic treatment with intravenous colistin and oral hydroxychloroquine.

The findings on the CT-scan of April 23, 2020, were described as signs of cystic fibrosis with primary involvement in the right upper lobe and results suggestive of moderate degree coronavirus pneumonia due to the presence of patchy opacities in ground glass of subpleural distribution that compromises mainly the right lower lobe and to a lesser extent in the segments of the lingula and the anterior segment of the left upper lobe (Fig. 1).

The RT-PCR took at the admission was negative, and on April 25, 2020, three days later, she was discharged, with significant improvement in the symptoms of admission. She was instructed to continue with colistin for seven days and to stop hydroxychloroquine.

The patient lives with a sister, a grandmother, and her mother. The study of antibodies against SARS-CoV-2 and the nasopharyngeal sample for RT-PCR of the mother were negative. No tests were done to the sister or grandmother, and they remain asymptomatic.

\section{DISCUSSION}

There is very little information about SARS-CoV-2 infection in CF patients. To date, very few cases have been reported in Europe: five patients in France, 7 in Great Britain, 5 in Germany, 3 in Spain and 1 in Italy, most of the adults and with a mild SARS-CoV-2 infection, without a marked

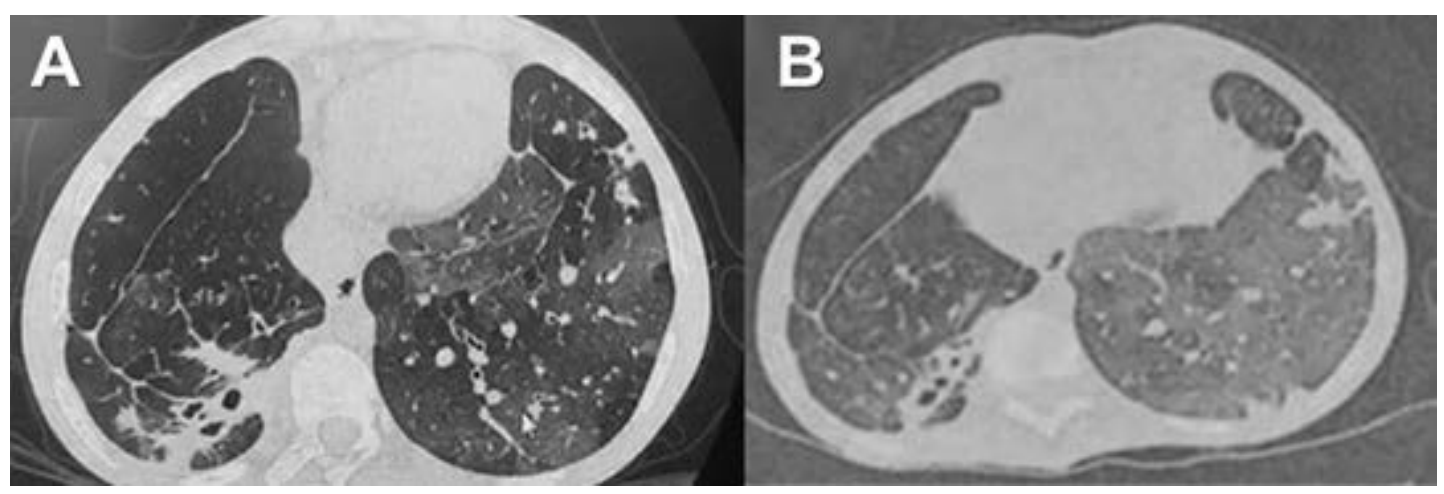

Fig. 2. A. CT-scan of September 2019. B. CT-scan of April 2020. Both show patched opacities in the ground glass of subpleural distribution. 
impact on the functional status of CF patients ${ }^{7,8}$, therefore we cannot establish or identify risk factors or protective factors.

It is recognized that viral infections in patients with cystic fibrosis are a factor of poor prognosis and deterioration of lung function and increased frequency of PE and its severity ${ }^{2,7,9,10}$. The symptoms of a SARS-CoV-2 infection differ from the symptoms of PE that most patients with cystic fibrosis know how to recognize ${ }^{5,7}$. Another question is to understand what is the role of azithromycin as a treatment since CF patients use it for long periods as immunomodulators $s^{4,7,11}$.

The evolution of the symptoms suggests that the patient did not present a SARS-CoV-2 infection because at admission the patient only had three days of symptoms and suggestive tomography, so the RT-PCR should be positive since the viral RNA is positive up to 3 weeks after acute clinical manifestations ${ }^{12-14}$, the detection of antibodies also negative or only positive IgM antibody. On the contrary, she had a positive IgG antibody, negative IgM, and negative RT-PCR or recovery phase of the disease.

The presence of ground-glass opacities may indicate an early acute phase of COVID-19, however, in patients with chronic lung diseases such as CF, they may also indicate an acute inflammatory process within PE or the disease's chronic lesions, becoming a confounding factor when treating and evaluating evolution in patients with this comorbidity. When comparing the tomography of September 2019 with the tomography of April 2020 (Fig. 2), we found that both present chronic lesions typical of cystic fibrosis and patches of ground glass patches of subpleural distribution in the basal lobes, which corresponds to the process chronic inflammatory $y^{2,9,15}$.

Another important fact is that the mother, in direct contact with the patient, presented RTPCR and negative antibodies, being the only person who could have infected the patient. Additionally, the sister and grandmother were asymptomatic.

We believe that the acute symptoms of the patient and their rapid resolution are probably secondary to the severe elevation of $\mathrm{PaCO}_{2}$ that she presented, in addition to chronic infection with Pseudomonas aeruginosa, with a positive serology perhaps due to viral infections other than SARS-CoV-2 but of the Coronaviridae subfamily ${ }^{3-5,14}$. COVID-19 continues to be a diagnostic challenge ${ }^{16,17}$; clinical suspicion should be high ${ }^{18}$. However, emerging situations, such as the possibility of false-positive serological test ${ }^{19}$ have been raised with other conditions overlapping, especially immunological and infectious, as happen with dengue ${ }^{20}$, which in certain regions, such as Asia and Latin America is highly endemic ${ }^{19,21-23}$.

Viral infections are recognized causes of pulmonary exacerbation in CF patients. The SARS-CoV-2 pandemic is a new challenge for both doctors and CF patients, mainly its diagnostic and therapeutic approaches. Strict social isolation is the best preventive measure we have to avoid SARS-CoV-2 infection.

\section{ACKNOWLEDGMENTS}

None.

\section{CONFLICT OF INTEREST}

The authors declare that there is no conflict of interest.

\section{AUTHORS' CONTRIBUTION}

SPS and ACNS participated in the conception of the report and performed the interview, SPS, KAL, VPC, and AJRM developed the manuscript preparation, reviewed the bibliography, and made the critical revision of the manuscript. KD reviewed the bibliography, and made a critical revision of the manuscript. All the authors approved the final version.

\section{FUNDING}

None.

\section{ETHICS STATEMENT}

from the patient.

Written informed consent was obtained

\section{DATA AVAILABILITY}

Not applicable

\section{ICMJE STATEMENT}

All authors meet the ICMJE authorship 


\section{REFERENCES}

1. Elborn JS. Adult Care in Cystic Fibrosis. Semin Respir Crit Care Med. 2019;40(06):857-868. doi: 10.1055/s0039-3400289

2. Blanchard AC, Waters VJ. Microbiology of Cystic Fibrosis Airway Disease. Semin Respir Crit Care Med. 2019;40(06):727-736. doi: 10.1055/s-0039-1698464

3. Hoek RAS, Paats MS, Pas SD, et al. Incidence of viral respiratory pathogens causing exacerbations in adult cystic fibrosis patients. Scand J Infect Dis. 2013;45(1):6569. doi: 10.3109/00365548.2012.708942

4. Eymery M, Morfin F, Doleans-Jordheim A, et al. Viral respiratory tract infections in young children with cystic fibrosis: a prospective full-year seasonal study. Virol J. 2019;16:111. doi: 10.1186/s12985-019-1208-7

5. Flight $\mathrm{W}$, Jones $\mathrm{A}$. The diagnosis and management of respiratory viral infections in cystic fibrosis. Expert Rev Respir Med. 2017;11(3):221-227. doi: 10.1080/17476348.2017.1288102

6. World Health Organization. Coronavirus disease (COVID-2019) situation reports. https://www.who. int/emergencies/diseases/novel-coronavirus-2019/ situation-reports. Accessed April 1, 2020.

7. Colombo C, Burgel P-R, Gartner S, et al. Impact of COVID-19 on people with cystic fibrosis. Lancet Respir Med. 2020;8(5):E35-E36. doi: 10.1016/S22132600(20)30177-6

8. Poli P, Timpano S, Goffredo M, Padoan R, Badolato R. Asymptomatic case of Covid-19 in an infant with cystic fibrosis. J Cyst Fibros. 2020;19(3):E18. doi: 10.1016/j. jcf.2020.03.017

9. Goss CH. Acute Pulmonary Exacerbations in Cystic Fibrosis. Semin Respir Crit Care Med. 2019;40(06):792803. doi: $10.1055 / \mathrm{s}-0039-1697975$

10. Hoek RAS, Paats MS, Pas SD, et al. Incidence of viral respiratory pathogens causing exacerbations in adult cystic fibrosis patients. Scand J Infect Dis. 2013;45(1):6569. doi: 10.3109/00365548.2012.708942

11. Simmonds NJ, Cullinan P, Hodson ME. Growing old with cystic fibrosis - The characteristics of long-term survivors of cystic fibrosis. Respir Med. 2009;103(4):629-635. doi: 10.1016/j.rmed.2008.10.011

12. The COVID-19 Investigation Team. Clinical and virologic characteristics of the first 12 patients with coronavirus disease 2019 (COVID-19) in the United States. Nat Med. 2020;26:861-867. doi: 10.1038/s41591-0200877-5
13. He X, Lau EHY, Wu P, et al. Temporal dynamics in viral shedding and transmissibility of COVID-19. Nat Med. 2020;26:672-675. doi: 10.1038/s41591-020-0869-5

14. Huang AT, Garcia-Carreras B, Hitchings MDT, et al. A Systematic Review of Antibody Mediated Immunity to Coronaviruses: Antibody Kinetics, Correlates of Protection, and Association of Antibody Responses with Severity of Disease. Infectious Diseases (except HIV/AIDS); 2020. doi: 10.1101/2020.04.14.20065771

15. Bergeron C, Cantin AM. Cystic Fibrosis: Pathophysiology of Lung Disease. Semin Respir Crit Care Med. 2019;40(06):715-726. doi: 10.1055/s-0039-1694021

16. Arteaga-Livias K, Pecho-Silva S, Panduro-Correa $\mathrm{V}$, Rodriguez-Morales AJ. The dilemmas of the classification of SARS-CoV-2 infection without clinical manifestations: asymptomatic or presymptomatic. J Formos Med Assoc. 2020;119(7):1237-1238. doi: 10.1016/j.jfma.2020.05.009

17. Alvarez-Moreno CA, Rodriguez-Morales AJ. Testing Dilemmas: Post negative, positive SARS-CoV-2 RT-PCR - is it a reinfection? Travel Med Infect Dis. 2020;35:101743. doi: 10.1016/j.tmaid.2020.101743

18. Rodriguez-Morales AJ, Cardona-Ospina JA, GutierrezOcampo E, et al. Latin American Network of Coronavirus Disease 2019-COVID-19 Research (LANCOVID-19).

19. Yan Y, Chang L, Wang L. Laboratory testing of SARSCoV, MERS-CoV, and SARS-CoV-2 (2019-nCoV): Current status, challenges, and countermeasures. Rev Med Virol. 2020;30(3):e2106. doi: 10.1002/rmv.2106

20. Yan G, Lee CK, Lam LTM, et al. Covert COVID-19 and false-positive dengue serology in Singapore. Lancet Infect Dis. 2020;20(5):E536. doi: 10.1016/S14733099(20)30158-4

21. Navarro J-C, Arrivillaga-Henriquez J, Salazar-Loor J, Rodriguez-Morales AJ. COVID-19 and Dengue, coepidemics in Ecuador and other countries in Latin America: pushing strained health care systems over the edge. Travel Med Infect Dis. 2020:101656. doi: 10.1016/j.tmaid.2020.101656

22. Rodriguez-Morales AJ, Gallego V, Escalera-Antezana $J P$, et al. COVID-19 in Latin America: the implications of the first confirmed case in Brazil. Travel Med Infect Dis. 2020. doi: 10.1016/j.tmaid.2020.101656

23. Cimerman S, Chebabo A, da Cunha CA, RodriguezMorales AJ. Deep Impact of COVID-19 in the HealthCare of Latin America: the case of Brazil. Braz J Infect Dis. 2020;24(2):93-95. doi: 10.1016/j.bjid.2020.04.005 